\title{
New landscapes: thinking beyond community in the conceptualisation of online medical education
}

\author{
Ahmed Rashid, Kirsty Alexander, Ann Griffin \\ UCL Medical School
}

The training of doctors is an intensely social phenomenon that takes place not in an isolated vacuum, but rather through formal and informal groupings and networks. The notion of community is so dominant in the medical education literature and psyche that it seems strange to try to, or even want to, unpick it. Even a cursory search throws up a vast body of work examining how community impacts on the experiences of medical learners.

In this issue of Medical Education, McGrath et al. ${ }^{1}$ scrutinise a collection of papers which explicitly use the popular theory of Communities of Practice (CoP). They demonstrate that the use of this theory was commonly either misrepresentative or cosmetic and raise the important issue of 'theory dropping'. Just a couple of decades ago, medical education scholars were making impassioned cries for increased use of theory ${ }^{2}$ and this study suggests that the pendulum may, in some ways, have over swung.

Aside from the broader issue of theoretical misappropriations, McGrath et al.'s paper also prompts a re-examination of the specific notion of community within medical education scholarship. For example, much of the work on community carries a fundamental assumption that it is universally positive: the explicit focus on teamwork, communication, and interdisciplinary learning within medicine all promote a belief that community is categorically and universally desirable and constructive. We know, however, that communities can have detrimental effects on learning, and delimiting and labelling them can be an arduous and contentious task ${ }^{3}$. Additionally, the focus on individual communities often ignores the complexity of the medical training world, with its overlapping and competing networks that rapidly change with each placement, rotation, or even individual work shift.

A further challenge to traditional notions of community is to question whether these apply to online networks. Much has changed in the three decades since Lave and Wenger first described CoP ${ }^{3}$. Perhaps most notably, the almost ubiquitous use of the internet. It has created a smaller world, but not necessarily a more neighbourly one. Although the technological utopians dreamt that greater connectivity would help humankind reach new heights of social cohesion and reconciliation, the internet has exposed the best and worst of the human condition. In the modern, digital world that we face, do medical educators need to rethink how community relates to learning? 
In considering this question, we may be wise to move beyond CoP and think instead in terms of landscapes of practice. A landscape of practice features multiple communities with complex interconnections and boundaries and, rather than being static, these communities of practice "arise and disappear, evolve, merge, split, compete with or complement each other, ignore or engage the other $^{\prime \prime 4}$. Landscapes of practice therefore better encapsulate learning in contemporary contexts; including virtual environments.

Although much online learning happens in formal educational spaces, the informal learning that takes place through social media platforms is comparatively less examined and potentially more revealing when considering communities and landscapes. Informal learning landscapes have emerged as an increasingly influential platform for professional education, including for doctors in undergraduate and postgraduate training and beyond ${ }^{5}$. As well as providing an opportunity to keep up with the latest trends and feast on a veritable smorgasbord of information and entertainment, social media also presents direct opportunities for friendship and networking. Although the human desire for engagement and collaboration is not new, social media undoubtedly represents a new form of landscape with boundaries that are yet to be examined.

A notable example of social media education comes in the form of virtual journal clubs ${ }^{6}$. This modern twist on a historical medical tradition has become highly popular in almost all medical specialties from radiology to obstetrics to nephrology. These learning events are commonly imagined as a shared experience by a community of harmonious professionals. This image hinges, however, on traditional assumptions of homogeneity and locality within the group - assumptions that are grounded in the deeply tribal nature of the medical profession and the shared technical expertise of particular subgroups. These assumptions ignore that online participants may come from a variety of different health systems, organisational structures, training systems, and work in different cultural and socioeconomic settings. The boundaries of this community will therefore partly be shaped by personal factors such as the public personas that individual participants have established on the particular platform, as well as systematic factors, including the professional regulations that might govern social media use within their countries. Resultingly, the online landscape transforms boundaries within the learning experience and challenges traditional assumptions of community. Another example arises from doctors sharing advice online. In previous work examining the advice given to new doctors on Twitter using \#tipsfornewdocs, we demonstrated that doctors from a variety of grades and specialties, as well as non-medical health professionals and even patients share advice through this movement ${ }^{7}$. The content of the advice varied broadly, from humorous to solemn, and from profound to mundane. Tweets originated from many different countries. By 
changing the lens from community to landscape, we may consider the extent to which the new doctors receiving each piece of advice journey through the multiple different communities from which it has arisen, noting the rules, values, and norms of each. For example, the comments might highlight strong differences in the socialisation processes of various doctor communities, the technical know-how foregrounded by the nursing and pharmacy communities, and the impassioned focus on values from patient communities. New entrants to the medical profession are thus being introduced to the hybridisation and multiplicity that may shape their own landscape of practice through these online platforms.

Neoliberal influences within the healthcare and higher education sectors seem to be squeezing out formal opportunities for informal learning, for example, via the removal of doctors' messes and protected time for departmental journal clubs. This creates a growing space for social media and online networking to occupy. There is, therefore, a pressing need for us to better understand the circumstances that allow medical students and doctors to thrive when learning online. Viewed through the lens of landscapes of practice, the complex and constantly evolving nature of online learning encounters provides fruitful opportunities for future research, and helps us to re-examine and re-imagine the notion of CoPs within the fast-paced and changeable world of contemporary medical education. 
1 McGrathet al. You say it, we say it, but how do we use it? Communities of practice: A critical analysis.. Med Educ.. 2020; 54( 3): 188- 195.

2 Van Der Vleuten CPM, Dolmans DHJM, Scherpbier AJJA The need for evidence in education. Med Teach. 2000;22(3):246-50.

3 Lave J, Wenger E. Situated learning: legitimate peripheral participation. Learning in doing. Cambridge England; New York: Cambridge University Press; 1991.

4 Wenger-Trayner E, Fenton-O'Creevy M, Hutchinson S, Kubiak C, Wenger-Trayner B, eds. Learning in landscapes of practice: Boundaries, identity, and knowledgeability in practice-based learning. Routledge; 2014 .

5 Cheston CC, Flickinger TE, Chisolm MS. Social media use in medical education: a systematic review. Acad Med. 2013;88(6):893-901.

6 Topf JM, Sparks MA, Phelan PJ et al. The evolution of the journal club: from Osler to Twitter. American Journal of Kidney Diseases. 2017;69(6):827-36.

7 Rashid MA, McKechnie D, Gill D. What advice is given to newly qualified doctors on Twitter? An analysis of \#TipsForNewDocs tweets. Med Educ. 2018;52(7):747-56. 